Supporting Information

\title{
Aggregation Properties of Heavy Atom Substituted Squaraine Dyes: Evidence for the Formation of J-Type Dimer Aggregates in Aprotic Solvents
}

Saji Alex, Meethale C. Basheer, Kalliat T. Arun, Danaboyina Ramaiah and Suresh Das*

Photosciences and Photonics Section, Chemical Sciences Division, Regional Research

Laborotary (CSIR), Trivandrum-695 019, India.

sdaas@rediffmail.com 


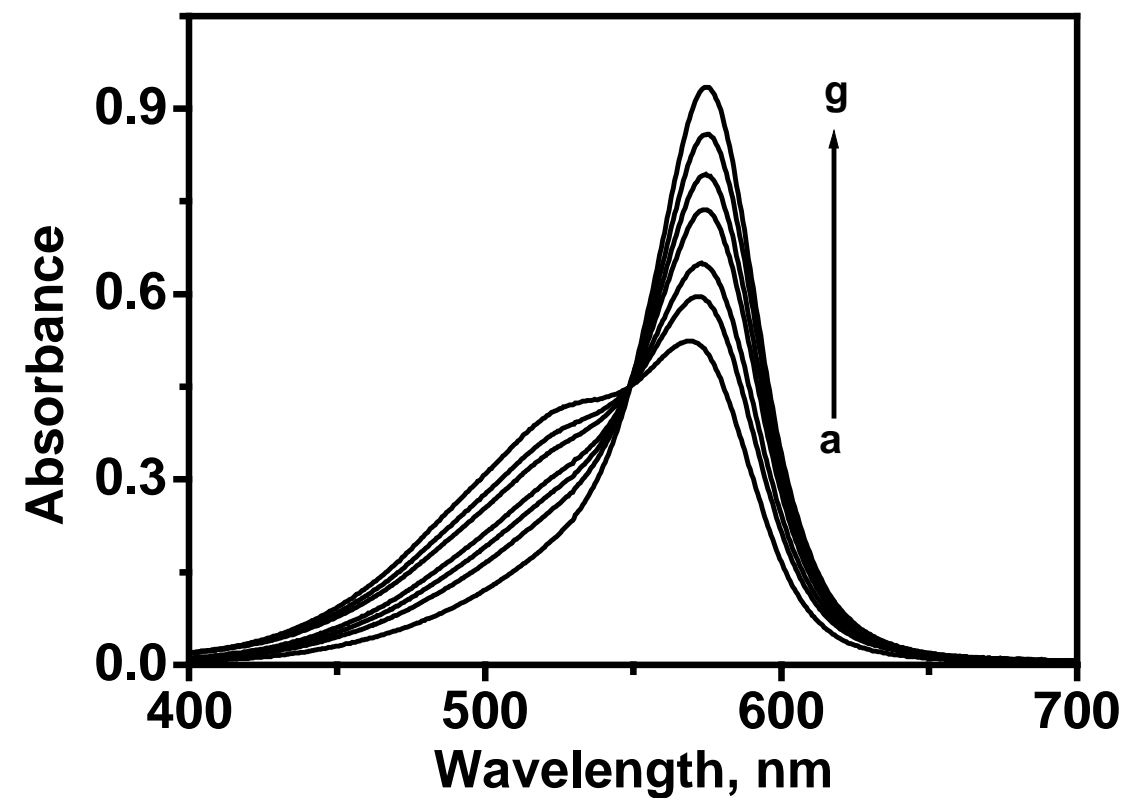

Figure S1. Effect of TFA on absorption spectra of SqI $(7.07 \mu \mathrm{M})$ in acetonitrile. [TFA]: a) 0.86 , b) 2.58 , c) 4.3 , d) 7.74 , e) 10.8 , f) 21.5 , g) $81.7 \mathrm{mM}$.

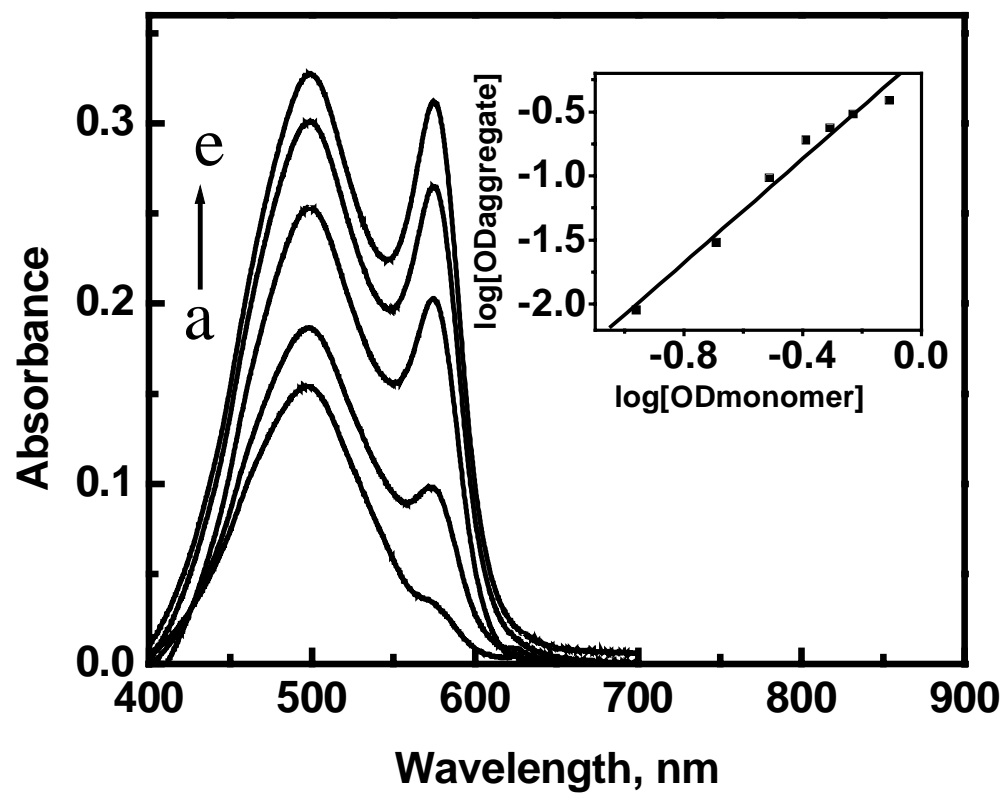

Figure S2. Absorption spectra of $\mathbf{S q B r}$ in acetonitrile at different concentrations recorded in a $0.5 \mathrm{~cm}$ cell. [SqBr]: a) 5.9, b) 19.8, c) 29 and d) $37.2 \mu \mathrm{M}$. Inset shows plot of $\log \left[\mathrm{OD}_{\text {aggregate }}\right]$ versus $\log \left[\mathrm{OD}_{\text {monomer }}\right]$ for $\mathrm{OD}$ measured at $497 \mathrm{~nm}$ and $572 \mathrm{~nm}$ for the monomer and aggregate, respectively. 


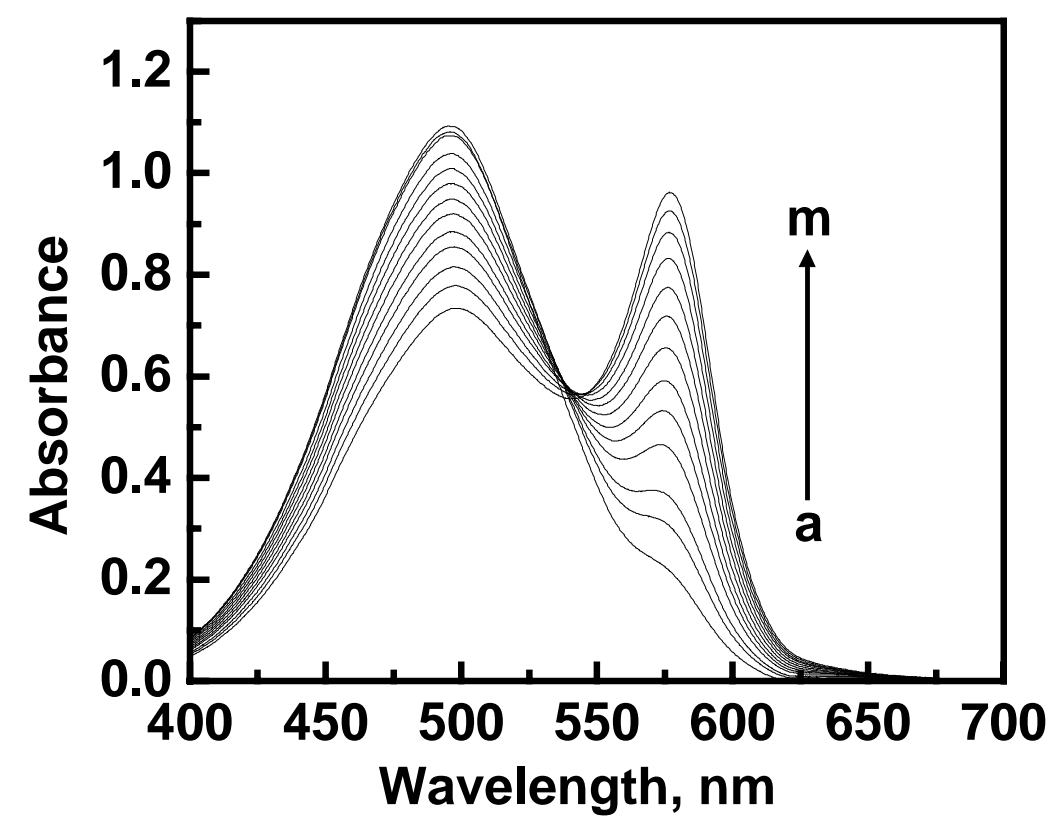

Figure S3. Effect of TFA on absorption spectra of $\mathbf{S q B r}(18 \mu \mathrm{M})$ in acetonitrile. [TFA]: a) 0 , b) 0.18 , c) 1.81 , d) 3.62 , e) 5.6 , f) 7.2 , g) 10.3 , h) 13.7 , i) 16.8 , j) 20.4 , k) 26.2 , l) 32.4 and $\mathrm{m}) 40.6 \mathrm{mM}$. 